\title{
Apelos discursivos em campanhas proporcionais na televisão
}

\author{
Luis Felipe Miguel*
}

\section{Resumo}

Nas eleições proporcionais, a utilização do Horário Gratuito de Propaganda Eleitoral (HGPE), pulverizada entre dezenas ou centenas de candidatos, torna-se menos efetiva. Ainda assim, ele cumpre importante funções: avisa aos eleitores que tal indivíduo é candidato e relembra a candidatura àqueles que já foram atingidos por outras formas de campanha, reforçando intenções de voto que, de outra forma, poderiam ser esquecidas. Além disso, pressupõe-se que, no tempo reduzido do HGPE, cada candidato buscará reforçar os elementos centrais de seu discurso de campanha. A pesquisa, realizada com base no horário eleitoral televisivo das eleições proporcionais do Distrito Federal (candidatos à Câmara Legislativa), buscou entender quais são as estratégias de utilização do HGPE por partidos e candidatos.

Palavras-chave: propaganda política, mídia e política, discurso político.

\section{Introdução}

$\mathrm{O}$

Horário Gratuito de Propaganda Eleitoral (HGPE) é considerado um importante instrumento de equalização das condições da disputa política no Brasil, reduzindo o peso tanto do poder econômico quanto dos controladores dos meios de comunicação de massa ${ }^{1}$. Ao dar aos partidos uma fatia da programação de rádio e

* Professor do Instituto de Ciência Política da Universidade de Brasília e pesquisador do CNPq. Endereço eletrônico: Ifelipemiguel@uol.com.br.

1 Uma versão anterior deste texto foi apresentada no I Congresso Anual da Associação Brasileira de Pesquisadores de Comunicação e Política, em Salvador, em dezembro de 2006. Agradeço as críticas e sugestões dos participantes do GT "Mídia e campanhas". Agradeço também a Aline Ohira e a Regina Dal- 
televisão, garante que todos tenham condições de apresentar sua mensagem ao eleitorado, da forma como julgam mais adequada, sem a edição que a mídia realiza. Ao ceder este espaço sem ônus para os partidos e segundo uma fórmula de equiidade ${ }^{2}$, reduz a influência do dinheiro na campanha eleitoral.

Nos estudos sobre a relação entre mídia e política no Brasil, o HGPE ocupa posição de destaque, em especial quando são enfocadas as eleições presidenciais (RUBIM \& AZEVEDO, 1998). A campanha de 1989 , a primeira escolha direta de presidente desde a ditadura, revelou as potencialidades da propaganda no rádio e na TV. A disputa no segundo turno ocorreu exatamente entre os dois candidatos que, cada um a seu modo, melhor se utilizaram dos meios eletrônicos e moldaram a linguagem da comunicação política no Brasil - Fernando Collor e Luiz Inácio Lula da Silva. Nas eleições seguintes, a capacidade de agendamento do horário eleitoral foi reduzida, o que se deve tanto ao aprendizado das emissoras, que se tornaram mais impermeáveis às estratégias dos candidatos (MIGUEL, 2004), quanto à progressiva pasteurização dos conteúdos, com o predomínio das técnicas de marketing político. Ainda assim, a janela de visibilidade que o HGPE proporciona é considerada crucial - é o momento em que se concentram as ansiedades dos favoritos, que devem se mostrar capazes de consolidar sua liderança, e as esperanças dos azarões.

A pesquisa acadêmica tem dado pouca atenção aos efeitos do HGPE nas campanhas proporcionais - para a Câmara dos Deputados, Assembléias Legislativas estaduais e Câmaras de Vereadores municipais ${ }^{3}$. No entanto, a cada eleição, quase metade do tempo de exposição na mídia eletrônica é destinado a elas. Dadas as diferenças nas dinâmicas entre eleições majoritárias e proporcionais,

castagnè, bem como ao parecerista anônimo de Política \& Sociedade, pelos comentários e sugestões.

2 Equidade relativa, é bem verdade, uma vez que os partidos recebem parcelas diferentes de acordo com seu desempenho na eleição anterior - e a fórmula de cálculo não é neutra. Mas a distribuição do tempo de rádio e TV é independente do acesso ao poder econômico.

3 Entre as exceções estão Schmitt, Carneiro e Kushnir (1999) e Albuquerque, Steibel e Carneiro (2008). 
é razoável supor que, nestas últimas, o impacto da campanha no rádio e na TV seja bem menor.

$\mathrm{Na}$ concorrência para os postos do poder executivo ou para o Senado (cuja eleição também é majoritária) há um número relativamente pequeno de candidatos, que podem esperar uma razoável visibilidade. Há cobertura regular da imprensa sobre suas campanhas e fatias específicas do HGPE para cada um; o horário eleitoral é uma peça, importante, mas não exclusiva, da comunicação mediada entre o candidato e os votantes, devendo ser entendido na dinâmica de sua relação com a mídia convencional. Já os candidatos a deputado ou a vereador se contam, em cada eleição, às centenas. Salvo raras exceções, suas candidaturas tendem a ser ignoradas pela cobertura de imprensa e o tempo na campanha eletrônica é exíguo.

A relação entre candidato e partido ou coligação também é diferente. O sistema eleitoral brasileiro, de representação proporcional com listas abertas, personaliza fortemente a disputa; e leva cada candidato a, simultaneamente, competir contra seus colegas de partido ou coligação e depender dos votos deles para alcançar o coeficiente eleitoral. A competição interna impede, em geral, que haja uma campanha unificada para a lista de candidatos. Assim, a propaganda para as eleições proporcionais costuma tomar a forma de uma sucessão de pequenos "clipes", um desfile de rostos de candidatos que anunciam seu nome, seu número e a exposição taquigráfica de alguma idéia ou proposta. Há um jogo de força dentro de cada partido, em que os candidatos disputam segundos de propaganda no rádio e TV, bem como o controle sobre a forma da apresentação. Aqueles com maior capital político (e econômico, diga-se de passagem) conseguem, em geral, mais tempo e uma identidade visual própria, ao passo que os outros muitas vezes não conseguem mais do que poucos segundos, num padrão de cenário e caracteres fixo para todo o partido.

A capacidade de distribuição do tempo de exposição no HGPE proporcional pode ser um importante recurso de poder nas mãos dos dirigentes partidários, que estão em condição de privilegiar aqueles candidatos que se mostram mais leais à organização ou ao grupo dominante dentro dela. O tempo de propaganda consiste, assim, num incentivo seletivo, simultaneamente material e de status (pois 
indica prestígio interno), segundo a terminologia que, a partir de Olson, foi cunhada por Panebianco (2005). De acordo com Schmitt, Carneiro e Kuschnir (1999), a divisão do tempo entre os candidatos representa a maneira informal que as direções partidárias têm, no Brasil, de ordenar as listas de candidaturas. A hipótese é demasiado exigente, uma vez que a idéia de "ordenamento da lista" implica na crença de que o eleitorado responde de forma razoavelmente mecânica ao tempo de exposição.

Por outro lado, convém anotar que os dirigentes partidários não têm controle total sobre o tempo de exposição na propaganda no rádio e televisão. Dado o imperativo de obter votos para a lista, candidatos independentes ou rebeldes, mas que possuam viabilidade eleitoral, não podem ser excluídos ou marginalizados sem que o partido sofra um pesado ônus. A distribuição do tempo, assim, não é uma decisão de um único grupo dirigente, mas a resultante de jogos de poder internos ao partido, confirmando, aqui, a regra de que "o controle sobre as zonas de incerteza [partidárias] não pode ser monopolizado in toto por um único grupo" (PANEBIANCO, 2005, p.70).

Some-se a isso o fato de que, por importante que seja, o HGPE não é necessariamente um recurso decisivo nas eleições proporcionais. A pulverização do tempo de vídeo entre tantos candidatos o torna menos efetivo. Assim, eles ainda dependem pesadamente de formas "pré-televisivas" de campanha (porta a porta, reuniões em clubes e associações, "santinhos"). Para muitos candidatos, a natureza da difusão do HGPE, que atinge um público indiferenciado, pouco acrescenta a campanhas focadas em grupos sociais específicos, definidos por vinculação corporativa e/ou local de residência.

Mas o horário eleitoral cumpre potencialmente três funções nas campanhas proporcionais. Em primeiro lugar, avisa aos eleitores que tal indivíduo é candidato, de uma forma mais eficaz que outros instrumentos de propaganda. Permite, assim, que o candidato entre no cardápio de opções do público. Em seguida, relembra a candidatura àqueles que já foram atingidos por outras formas de campanha, reforçando uma intenção de voto que, de outra forma, poderia ser esquecida. Por fim, pressupõe-se que, no tempo reduzido do HGPE, cada candidato buscará reforçar os elementos centrais de seu discurso de campanha. 
Esta última característica torna a campanha às eleições proporcionais no rádio e na televisão potencialmente interessante para a pesquisa. Ela reuniria, num corpus pequeno e acessível, o conjunto dos apelos discursivos centrais dos candidatos, indicando que maneira cada um deles busca sensibilizar o eleitorado.

Este artigo apresenta dados de pesquisa realizada com o HGPE das eleições proporcionais do Distrito Federal ${ }^{4}$. Foram assistidos e tabulados todos os programas eleitorais exibidos à noite com a campanha para o cargo de deputado distrital (correspondente a deputado estadual nas outras unidades da federação). Como a propaganda para a Câmara Legislativa do Distrito Federal era exibida três vezes por semana, às terças, quintas e sábados, o corpus analisado consistiu de 19 programas, com 20 minutos de duração cada um. Ao todo, 656 candidatos de 28 partidos competiram por 24 cadeiras, sendo que dez deles foram, ao final, impugnados; nem todos, porém, apareceram no horário eleitoral noturno. Para cada inserção de propaganda de um candidato foram identificados os principais apelos dirigidos ao eleitorado e preenchida uma ficha, cujos dados eram, em seguida, inseridos no software estatístico Sphinx Lexica.

A primeira seção do artigo delineia o contexto da disputa, apresentando um quadro da política local do Distrito Federal. A segunda seção descreve o horário eleitoral noturno e apresenta as correlações com os resultados. A terceira seção, enfim, analisa as temáticas privilegiadas pelos candidatos em seus programas, seguindo-se a ela uma breve conclusão.

\section{A política do Distrito Federal}

A capital brasileira conquistou o direito de eleger representantes à Câmara Federal e ao Senado após o fim do regime militar,

4 Trata-se de uma das vertentes projeto de pesquisa "Determinantes de gênero, visibilidade midiática e carreira política no Brasil”, apoiado pelo $\mathrm{CNPq}$ com dotações dos editais no 45/2005 e 61/2005, além de uma bolsa de Produtividade em Pesquisa. Os dados foram colhidos por Aline Marques Ohira, voluntária do Programa de Iniciação Científica da UnB, com a colaboração de Aline de Almeida Coutinho, bolsista de Iniciação Científica do $\mathrm{CNPq}$, às quais agradeço pela dedicação e competência num trabalho exaustivo e ingrato. 
vivendo sua primeira eleição em 1986. A Constituição de 1988 concedeu autonomia política e administrativa ao DF, que em 1990 elegeu pela primeira vez seu governador e também o parlamento local, a Câmara Legislativa. Ao contrário do que ocorre nas outras unidades da federação, não existe governo municipal - Brasília e suas "cidades satélites" possuem administradores nomeados pelo governador, sem nenhuma espécie de parlamento local. A carreira política, portanto, conta com degraus a menos, o que, sem dúvida, possui impacto na dinâmica da política distrital.

Em todo o período pós-redemocratização, a figura dominante da política local tem sido Joaquim Roriz, um deputado do PMDB goiano que, em 1988, foi nomeado governador do Distrito Federal pelo então presidente José Sarney. Em 1990, Roriz tornou-se o primeiro governador eleito; venceria também as eleições de 1998 e 2002. Sua popularidade se apóia em políticas assistenciais para a população de baixa renda, em especial a doação de lotes urbanos (o que lhe vale a acusação de ser responsável pelo "inchaço" da capital), e na realização de grandes obras viárias. Sempre filiado ao PMDB (foi fundador do PT em Goiás, mas logo trocou de partido), ele incorporou a seu grupo políticos integrantes de outras legendas de centro-direita, como PFL, PTB, PP e PSDB. Os partidos mais à esquerda ganharam, em grande medida, uma identidade construída no negativo - formando o pólo "anti-Roriz" da política brasiliense. Embora outras agremiações possuíssem lideranças de peso, o centro deste pólo foi sendo ocupado pelo Partido dos Trabalhadores, em parte como reflexo de um movimento nacional que fez do PT o núcleo da esquerda no país, em parte pelo controle que exercia sobre os sindicatos locais, em especial os do funcionalismo público. Esta centralidade se consolidou com a surpreendente eleição para o governo local, em 1994, do candidato petista, o professor Cristovam Buarque.

Nas eleições de 2006, este quadro esteve alterado. Concluindo seu segundo mandato consecutivo, Joaquim Roriz não podia concorrer à reeleição e seu grupo não conseguiu chegar a um nome de consenso para o cargo. Em função dos anos de hegemonia na política local, havia um excesso de postulantes aos cargos majoritários, o que gerou cisões na base de apoio. O PSDB, após muita 
controvérsia, lançou o nome da vice-governadora Maria de Lourdes Abadia, com apoio do PMDB, do PTB e de cinco microlegendas (PAN, PHS, PTC, PRP e PTdoB); o candidato do PFL, escolhido após desgastante disputa interna, foi o deputado federal José Roberto Arruda, apoiado por PP, PPS, PL, PRONA, PMN, PSC e PTN. O fato de que Arruda havia pertencido ao PSDB, partido que trocou pelo PFL, não contribuiu para promover a unidade da base de apoio do governo local. Candidato ao senado pelo PMDB, Roriz sustentou oficialmente o nome de Abadia, mas recebeu apoio informal também da coligação que sustentava Arruda.

A presença do PPS na coligação em favor de Arruda já sinaliza a ruptura da frente de esquerda no Distrito Federal. O PT lançou a candidatura da deputada distrital Arlete Sampaio, dobrando as pretensões do $\mathrm{PCdoB}$, que pretendia emplacar o nome do então ministro dos Esportes, Agnelo Queiroz. A candidata petista foi apoiada também por PSB, PV, PRB e PRTB. Os outros três candidatos contavam com pouca expressão eleitoral: Toninho, do PSOL, dissidência à esquerda do PT, apoiado por PSTU e PCB; Fátima Passos, do PSDC; e Expedito Mendonça, do PCO. O PDT absteve-se de apoiar qualquer candidato, mas havia lançado à Presidência da República um político local, o ex-governador Cristovam Buarque, que abandonara o PT anos antes.

A fim de viabilizar o lançamento de um maior número de candidaturas, cada uma das principais coligações para o governo do Distrito Federal repartiu-se em várias na disputa para a Câmara Legislativa. Assim, em favor de Abadia concorreram quatro listas de candidatos a deputado distrital: PSDB/PAN, PMDB/PTdoB, PTB/PHS e PRP/PTC. Arruda contou com outras quatro listas, formadas por PFL/PTN, PP/PSC, PL/PPS e PMN/PRONA. E Arlete Sampaio foi apoiada por duas, PCdoB/PV/PSB/PRTB e PT/PRB.

José Roberto Arruda foi eleito no primeiro turno, com $663 \mathrm{mil}$ votos, isto é, 50,3\% do total de votos válidos. Secretário de Obras na segunda gestão de Roriz (a partir de 1991), Arruda elegeu-se senador em 1994. Envolvido no caso da violação do painel do Senado Federal, quando da cassação de Luiz Estevão, renunciou ao mandato em 2000. O escândalo, porém, não afetou negativamente sua carreira política. Em 2002, elegeu-se deputado federal com votação 
recorde - obteve cerca de um em cada quatro votos válidos para a Câmara dos Deputados no Distrito Federal - e credenciou-se para disputar o governo em 2006.

Maria de Lourdes Abadia ficou em segundo lugar, com 315 mil votos, seguida por Arlete Sampaio, com 275 mil. O fraco desempenho do PT, que reduziu sua votação para o governo e suas bancadas federal e distrital, é explicável, em grande medida, pelo desgaste do partido - que passara a controlar o executivo federal - junto à sua base tradicional no funcionalismo público, levando ao afrouxamento de seus elos com os sindicatos, bem como à sensibilidade de parte do eleitorado local, bastante politizado, à crise ética que afetava os petistas.

Joaquim Roriz elegeu-se senador com 657 mil votos, contra 544 mil de seu principal oponente, o ex-ministro Agnelo Queiroz, do $\mathrm{PCdoB}^{5}$. A bancada de oito deputados federais ficou divida entre os partidos que apoiaram Abadia (dois eleitos do PMDB e um do PTB), Arruda (dois do PFL e um do PPS) e Arlete (um do PT e outro do PSB). Para a Câmara Legislativa, ao todo 14 partidos obtiveram representação. As maiores bancadas foram eleitas por PT e PFL (quatro deputados distritais cada), seguidos de PMDB (três) e PTB e PSDB (dois cada). PDT, PL, PSB, PPS, PP, PRONA, PSL, PRP e PMN elegeram um deputado cada.

\section{O HGPE noturno para distrital}

Dos 656 candidatos que disputaram a Câmara Legislativa do Distrito Federal em 2006, 610 apareceram na propaganda eleitoral noturna na televisão. Quatro candidatos apareceram em todos os 19 programas; a maioria $(62,2 \%)$ frequientou a telinha entre uma e três vezes. Em média, os candidatos eleitos apareceram 9,7 vezes cada, bem mais do que os derrotados (2,7 vezes cada $)^{6}$. Somados todos os

5 A coligação que apoiou Arruda aderiu à campanha de Roriz, mas teve um candidato pro forma ao senado, Marcos Cardoso, que obteve menos de 17 mil votos.

6 Os candidatos indeferidos pela Justiça Eleitoral surgiram na TV, em média, 3,3 vezes cada um. 
programas, os eleitos ocuparam, em média, 161 segundos de tempo de propaganda, contra 22 segundos dos não-eleitos. A correlação entre o tempo de TV e o número de votos obtidos pelo candidato chega a $+0,68$, número que não é especialmente impressionante, mas tampouco é desprezível ${ }^{7}$.

Gráfico 1: Relação entre tempo de exposição no HGPE noturno e votação obtida

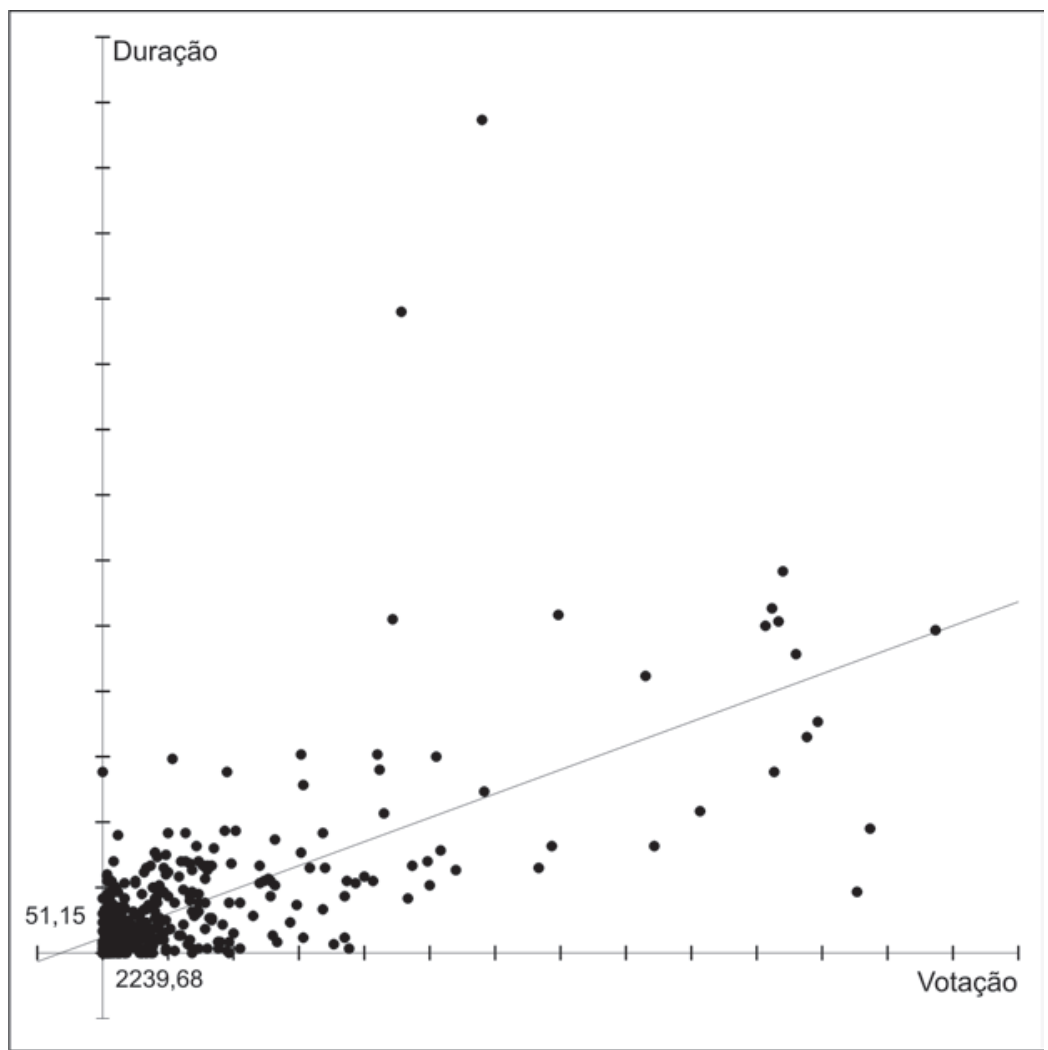

Fonte: pesquisa "Determinantes de gênero e carreira política no Brasil"

Estudando campanhas no Rio de Janeiro, Schmitt, Carneiro e Kuschnir alcançam correlações de +0,53 em 1994 (eleição estadual)

7 Para o cálculo, foram retirados os candidatos indeferidos, cujos votos não foram computados pela Justiça Eleitoral. 
e +0,50 em 1996 (eleição municipal) ${ }^{8}$. Quando o cálculo é feito entre tempo de TV e votação dos partidos, e não mais dos candidatos individuais, os números a que eles chegam sobem para $+0,64$ e $+0,78$, respectivamente, o que os leva a afirmar que

a representação da competição eleitoral que emerge desta análise sugere a configuração de um sistema no qual estão presentes não apenas candidatos isolados, envolvidos exclusivamente com a promoção de suas reputações individuais, mas partidos que atuam como agentes efetivos na definição dos resultados eleitorais (SCHMITT, CARNEIRO \& KUSCHNIR, 1999, p. 294).

A rigor, o que eles estão afirmando é que os partidos tendem a maximizar o tempo de exposição dos candidatos com maior potencial eleitoral, o que lhes permitiria produzir a relação voto/ segundo de tela mais vantajosa para a lista como um todo. (No caso das eleições para a Câmara Legislativa do Distrito Federal em 2006, a correlação entre tempo de TV e votação dos partidos chegou a $+0,92^{9}$.) No entanto, isto não implica em afirmar que as direções partidárias têm capacidade de hierarquizar os candidatos - elas podem, na verdade, estar na posição de reféns daqueles que controlam mais votos, constrangidas a dar-lhes mais destaque a fim de vencer a barreira do quociente eleitoral e ampliar a bancada. Utilizando as categorias de Pierre Bourdieu, é possível dizer que as listas fechadas valorizam as posições de cada agente no interior do próprio campo político, ao passo que as listas abertas, como no Brasil, dão maior peso às relações do agente com aqueles que estão excluídos do campo (os simples eleitores).

É necessário enfatizar que os dados não permitem estabelecer uma relação de causalidade entre a presença no HGPE e o êxito

8 Nas eleições municipais cariocas de 2004, a correlação foi calculada em $+0,61$ (ALBUQUERQUE, STEIBEL \& CARNEIRO, op.cit., p. 475). Não é possível afirmar se o salto de 1996 para 2004, em dois pleitos similares, corresponde a uma tendência, vinculada às estratégias dos partidos e/ou ao comportamento do eleitorado, ou é um mero deslocamento errático, devido a circunstâncias externas.

9 As correlações menores para o Rio de Janeiro se explicam, provavelmente, por se tratar de cidade mais populosa, com uma política local mais disputada e mais complexa do que a do Distrito Federal. 
eleitoral. O fato de que há uma proporção maior de eleitos entre os candidatos com maior visibilidade na televisão tanto pode indicar que a maior exposição rendeu mais votos quanto que os partidos optam por dar mais destaque àqueles que parecem ter maior potencial eleitoral. A alta correlação entre presença na TV e votação dos partidos se explica também pelo fato de que a distribuição do tempo do HGPE entre os partidos depende do desempenho de cada um na eleição anterior, isto é, as legendas com mais tempo são aquelas que já tiveram mais votos antes.

Cumpre observar que, entre os quatro candidatos a deputado distrital que apareceram em todos os programas eleitorais noturnos, dois não se elegeram ${ }^{10}$. Na outra ponta, um candidato que apareceu uma única vez, ocupando quatro segundos, chegou à Câmara Legislativa - é verdade que como o menos votado de todos, "puxado" pela legenda. Entre aqueles que nunca apareceram nos programas noturnos da TV, a maior parte obteve votação irrisória, mas oito ultrapassaram a barreira dos mil votos e um deles chegou a mais de 4 mil (o último eleito obteve menos de 7 mil votos).

Entre os candidatos, 18 eram deputados distritais buscando a reeleição, dos quais 11 obtiveram êxito. Os deputados apareceram, em média, 11,6 vezes cada um no horário eleitoral noturno, ocupando 173 segundos, contra 2,8 vezes e 23 segundos dos novos postulantes.

As mulheres somavam $20,1 \%$ dos candidatos, sendo eleitas três (12,5\% dos eleitos). As candidatas tiveram uma exposição média menor no HGPE noturno - 2,7 vezes e 24 segundos, enquanto os homens apareceram 3,3 vezes e 31 segundos cada. Em todos os partidos, com exceção de PCdoB, PV e PAN, a exposição média dos homens foi maior. A tabela 1 indica que, para as mulheres, a presença no horário eleitoral parece ser um recurso mais crucial do que para os homens.

10 Um deles obteve votação que o colocava entre os 24 primeiros, mas perdeu a vaga por conta do cálculo de proporcionalidade. 
Tabela 1: Inserções de candidatos à Câmara Legislativa no HGPE noturno de 2002, por sexo

\begin{tabular}{l|c|c|c|c}
\hline \multirow{2}{*}{} & \multicolumn{2}{|c|}{ Mulheres } & \multicolumn{2}{c}{ Homens } \\
\cline { 2 - 5 } & Eleitas & Não-eleitas & Eleitos & Não-eleitos \\
\hline Média de inserções por candidato & 14,3 & 2,1 & 9,0 & 2,9 \\
\hline $\begin{array}{l}\text { Duração total média por candidato } \\
\text { (em segundos) }\end{array}$ & 231 & 15 & 151 & 24 \\
\hline $\begin{array}{l}\text { Correlação entre tempo de TV e } \\
\text { votação }\end{array}$ & \multicolumn{2}{|c|}{$+0,91$} & \multicolumn{2}{|c}{$+0,64$} \\
\hline
\end{tabular}

Obs. No cálculo da correlação, foram eliminados os candidatos indeferidos pela Justiça Eleitoral.

Fonte: pesquisa "Determinantes de gênero, visibilidade midiática e carreira política no Brasil".

A diferença em número de inserções e tempo médio de exposição entre eleitos e não-eleitos é muito maior para as mulheres do que para os homens. Uma candidata eleita apareceu no vídeo, em média, 14,4 vezes mais que uma derrotada - já entre os homens o número cai para 5,3. Como o universo de deputadas eleitas é muito pequeno, os números são pouco significativos. A correlação entre tempo de TV e votação é mais eloquiente. $\mathrm{O}+0,91$ alcançado para as candidatas do sexo feminino indica uma altíssima dependência entre visibilidade no HGPE e desempenho nas urnas. Mais uma vez, os números não são capazes de explicitar uma relação causal. É possível que a menor votação das mulheres (média de 1311 votos por candidata, contra 2073 dos homens) reflita a sub-representação das candidatas na propaganda eleitoral. $\mathrm{Ou}$, ao inverso, apenas mulheres com potencial eleitoral muito forte conseguem obter espaço no vídeo - isto é, os partidos apostaram menos em candidaturas femininas.

Neste caso, a maior disparidade de tempo de vídeo entre as candidatas mulheres refletiria o conhecido fenômeno da sobrequalificação dos postulantes a cargos políticos que são pertencentes a grupos sociais subalternos. Na ausência desta sobrequalificação, que no caso corresponde a um potencial eleitoral já reconhecido, as mulheres seriam marginalizadas da campanha, uma vez que, entre vários candidatos com chances desconhecidas, os partidos prefeririam investir nos homens. 


\section{Os apelos discursivos}

A fim de identificar a maneira pela qual os candidatos buscavam conquistar o eleitorado, a pesquisa estabeleceu um repertório de "apelos discursivos". Após a realização de teste com amostra do corpus, foram definidos 14 diferentes apelos:

Biografia - os feitos passados ou a formação acadêmica e profissional do candidato são apresentados como credenciais para o mandato que ele almeja conquistar.

Corporação - o candidato se coloca como representante de uma determinada categoria profissional, à qual dará voz e cujos interesses defenderá no parlamento local.

Localidade - o candidato se coloca como representante de um determinado setor de moradia, prometendo, de maneira expressa ou implícita, defender no parlamento os interesses de seus habitantes.

Temática - quando o candidato afirma seu compromisso com determinada questão de importância pública (saúde, educação, segurança etc.), sem, no entanto, apresentar projetos de ação específicos ou ultrapassar generalidades do tipo "tudo pela saúde", "melhores escolas" ou "mais segurança". Mesmo uma inserção muito curta pode incluir diversos apelos temáticos: "Em defesa da educação, da juventude e do idoso".

Proposta - é a apresentação de um projeto específico, ainda que de maneira muito sumária ou superficial. Criação de um posto de saúde em determinada região é uma proposta, ampliação das vagas noturnas no ensino médio também e assim por diante.

Mudança/renovação - crítica genérica ao estado da política atual e/ou da Câmara Legislativa em particular, com a indicação, explícita ou não, de que o candidato representa uma transformação das práticas viciadas.

Partido - ênfase no compromisso partidário, na lealdade do candidato para com sua agremiação, cujo programa deve ser representado.

Ideologia - defesa de um conjunto de princípios abstratos relativos à organização social, como "economia de mercado", "socialismo" ou "feminismo". 
Movimento social - o candidato enfatiza sua militância em algum movimento ou grupo da sociedade civil.

Oposição/situação local - o candidato busca se credenciar como futuro representante por sua posição em relação ao governo do Distrito Federal, seja como apoiador, seja como crítico.

Oposição/situação federal - o mesmo que a anterior, em relação ao governo da União.

Vinculação a candidato majoritário - o candidato se apresenta como próximo a um dos candidatos a cargos majoritários. Em geral, a vinculação é com o candidato ao governo, gerando um discurso de garantia de base de sustentação no legislativo ("Fulano precisa de mim na Câmara Legislativa”), embora também possa ocorrer com candidatos à presidência e, no caso da eleição de 2006 no Distrito Federal, com Joaquim Roriz, candidato ao Senado.

Apoio recebido - é anunciado o apoio de personalidades da política ou de outros campos àquele candidato.

Religião - o candidato apresenta sua vinculação com alguma religião organizada e/ou se coloca na posição de defensor de determinados valores religiosos.

Apelo folclórico - o candidato tenta se destacar no horário eleitoral por meio de uma apresentação pessoal bizarra ou extravagante.

Acrescenta-se à lista "nenhum apelo", que abriga os casos - aliás, frequientes - de inserções que se limitavam a enunciar o número e o nome do candidato, sem nada mais, cumprindo exclusivamente a função, descrita acima, de anunciar/relembrar a existência da candidatura. Cabe observar que, na tabulação dos dados, não foram considerados possíveis apelos que pudessem estar incorporados no nome do urna dos candidatos. Isto é, só se considerava que - por exemplo - Kamel do PV apresentava um apelo "partidário", Pastora Rute um apelo "religioso" ou Coronel Maynarde um apelo "corporativo" caso este elemento estivesse presente, de alguma outra maneira, em seu discurso.

Foram, ao todo, 1996 inserções de candidatos nos 19 dias de HGPE para deputado distrital, isto é, em média mais de 100 candidatos apareceram por dia de exibição da propaganda eleitoral. Como mostra a tabela 2, os apelos temáticos são predominantes, 
seguidos da categoria "nenhum". O discurso da renovação mostra uma presença importante; já a quantidade de apelos vinculados a partido, ideologia, oposição e situação - todas categorias ligadas à dinâmica interna do próprio campo político - é irrisória.

Tabela 2: Presença dos apelos discursivos nas inserções de candidato à Câmara Legislativa do DF no HGPE noturno de 2006

\begin{tabular}{l|l|l}
\hline temática & 842 & $42,2 \%$ \\
\hline proposta & 348 & $17,4 \%$ \\
\hline biografia & 311 & $15,6 \%$ \\
\hline mudança/renovação & 234 & $11,7 \%$ \\
\hline corporação & 147 & $7,4 \%$ \\
\hline localidade & 106 & $5,3 \%$ \\
\hline religião & 45 & $2,3 \%$ \\
\hline candidato majoritário & 43 & $2,2 \%$ \\
\hline apelo folclórico & 42 & $2,1 \%$ \\
\hline apoio & 30 & $1,5 \%$ \\
\hline oposição/situação local & 9 & $0,5 \%$ \\
\hline partido & 6 & $0,3 \%$ \\
\hline ideologia & 3 & $0,2 \%$ \\
\hline movimento social & 2 & $0,1 \%$ \\
\hline oposição/situação federal & 1 & $0,1 \%$ \\
\hline nenhum & 460 & $23,0 \%$ \\
\hline
\end{tabular}

Obs. Havia possibilidade de indicação de mais de um apelo por inserção.

Fonte: pesquisa "Determinantes de gênero, visibilidade midiática e carreira política no Brasil".

Entre as corporações, as mais citadas foram policiais e bombeiros, lembrados em 39 inserções, seguidos de profissionais da saúde (24), professores (16), servidores públicos em geral (15) e rodoviários (9). A duração média das inserções variou significativamente de acordo com os apelos discursivos que continham, sendo maior para apelos vinculados a candidato majoritário (18 segundos), biografia (15 segundos), oposição ou situação em relação ao governo federal (14 segundos), apoio recebido (13 segundos) e proposta (12 segundos); e menor, como esperado, quando não havia nenhum apelo (4 segundos).

Proporcionalmente, há pouca diferença entre os sexos. As inserções das mulheres apresentam uma predominância significativamente maior de apelos temáticos $(56,9 \%$ contra $39,4 \%)$ e de vinculações a candidatos majoritários ( $4,3 \%$ contra $1,7 \%)$, o que se 
explica, em grande parte, pela candidatura de Jaqueline Roriz, filha de Joaquim Roriz. Os homens se destacam quanto aos apelos biográficos $(16,5 \%$ contra $10,8 \%)$ e corporativos $(7,8 \%$ contra $3,7 \%)$.

Os dados mostram também que os candidatos eleitos usaram, muito mais do que os não eleitos, o apelo de tipo biográfico. É de se supor que eles apresentam uma atividade política anterior maior, o que tanto amplia suas chances eleitorais quando viabiliza a utilização deste tipo de apelo na propaganda. Entre os deputados distritais buscando a reeleição, a presença de apelo biográfico em alguma inserção no HGPE noturno alcança $100 \%$, o que sinaliza para a utilização da propaganda eleitoral como veículo de prestação de contas do exercício do mandato, ainda que de forma bastante superficial.

Mas a análise da tabela 3, abaixo, exige cuidados. Sua unidade é o candidato, não - como na tabela 2 - a inserção. Como os eleitos tiveram um número médio de inserções significativamente maior do que os não eleitos, puderam apresentar também uma maior variedade de apelos discursivos. Além disso, os números absolutos são, por vezes, tão pequenos que qualquer análise sai enviesada.

Tabela 3: Apelos discursivos utilizados pelos candidatos à Câmara Legislativa do Distrito Federal no HGPE de 2006

\begin{tabular}{l|c|c}
\hline & Eleitos & Não eleitos \\
\hline temática & $91,7 \%(22)$ & $53,1 \%(330)$ \\
\hline nenhum & $29,2 \%(7)$ & $32,0 \%(199)$ \\
\hline proposta & $54,2 \%(13)$ & $23,6 \%(147)$ \\
\hline mudança/renovação & $33,3 \%(8)$ & $18,0 \%(112)$ \\
\hline biografia & $70,8 \%(17)$ & $12,1 \%(75)$ \\
\hline corporação & $12,5 \%(3)$ & $12,1 \%(75)$ \\
\hline localidade & $12,5 \%(3)$ & $8,7 \%(54)$ \\
\hline apelo folclórico & $16,7 \%(4)$ & $4,3 \%(27)$ \\
\hline candidato majoritário & $12,5 \%(3)$ & $3,2 \%(20)$ \\
\hline religião & $4,2 \%(1)$ & $3,2 \%(20)$ \\
\hline apoio & $4,2 \%(1)$ & $2,4 \%(15)$ \\
\hline partido & $0,0 \%(0)$ & $0,6 \%(4)$ \\
\hline oposição/situação local & $4,2 \%(1)$ & $0,3 \%(2)$ \\
\hline ideologia & $4,2 \%(1)$ & $0,2 \%(1)$ \\
\hline oposição/situação federal & $0,0 \%(0)$ & $0,2 \%(1)$ \\
\hline outro & $0,0 \%(0)$ & $0,2 \%(1)$ \\
\hline
\end{tabular}

Fonte: pesquisa "Determinantes de gênero, visibilidade midiática e carreira política no Brasil" 
Quando a análise é focada nos partidos, também não aparecem grandes discrepâncias. Para facilitar a análises dos dados, os partidos foram agrupados em "esquerda” (PT, PSB, PV, PDT, PSOL, PSTU, PPS, PCdoB, PCB, PMN, PCO e PHS), "centro" (PSDB e PMDB) e "direita" (PFL, PP, PTB, PL, PRONA, PRB, PSL, PRTB, PTdoB, PRP, PTN, PTC e PAN), seguindo a classificação usual na ciência política brasileira ${ }^{11}$. Para a maior parte das legendas, essa distinção indica cada vez menos a presença de diferenças programáticas expressivas, mas permanece como uma referência que, ainda que possua pouca ressonância no público, baliza o espaço político para os próprios integrantes do campo.

Os candidatos dos partidos de direita usam mais o discurso da mudança do que os outros ( $21,2 \%$ deles o incluem em pelo menos uma inserção, contra $15,2 \%$ na esquerda e $15,1 \%$ no centro), o que revela a diluição deste apelo - ainda mais quando se tem em mente que o governo do Distrito Federal estava em mãos de partidos de centro em aliança com partidos de direita. Em grande medida, ele aparece combinado com a valorização da "ética" na política. Por outro lado, na direita o uso de apelo religiosos é menor ( $2,4 \%$, enquanto na esquerda é $3,5 \%$ e no centro, $5,8 \%$ ), outro dado contra-intuitivo. A discrepância mais significativa, porém, diz respeito à utilização do apelo biográfico, que é muito forte entre os candidatos de partidos do centro (43\%), mas bem menos significativa para as outras posições (10,4\% na esquerda, $9,1 \%$ na direita). Uma explicação para isso é que PMDB e PSDB estiveram no controle do governo local nos últimos anos, seus integrantes tendo, portanto, uma folha corrida como "administradores" para exibir ao eleitorado.

Outra tentativa de compreensão dos dados passa pelo agrupamento dos partidos por seu porte. Foram considerados "grandes" o PFL, PMDB, PSDB e PT, agremiações que concentraram a disputa política local nos últimos pleitos e fizeram as maiores bancadas de deputados. Já PCdoB, PDT, PL, PP, PPS, PSB, PSOL e PTB, que são atores secundários nas eleições do Distrito Federal, mas possuem algumas lideranças de peso e precisam ser levados em conta no jogo, foram classificados como "médios". Os restantes formavam

11 Ver, por exemplo, Fernandes, 1995; Rodrigues, 2002; e Miguel e Machado, 2007. 
o pelotão dos "pequenos". As diferenças na predileção pelos apelos discursivos são pequenas, sendo significativas apenas em duas categorias, aliás já esperadas. Partidos grandes dão mais destaque aos apelos biográficos, uma vez que mais de seus candidatos puderam ocupar cargos. E os partidos pequenos concentram a categoria "nenhum apelo", uma consequiência da exiguiidade do tempo de que dispõem para apresentar seus candidatos.

\section{As temáticas de campanha}

Ao todo, 842 inserções adotaram "apelo temático", de acordo com as categorias estabelecidas para a pesquisa. Nelas, foram identificados 1347 apelos, uma média de 1,6 por inserção. A distribuição das temáticas, apresentada na tabela 4 , abaixo, pouco apresenta de surpreendente. Educação (presente em mais de um quarto das inserções que incluíam algum apelo temático), trabalho, saúde, segurança e ética são preocupações dominantes na política brasileira. Habitação e ocupação do solo, que formam a categoria seguinte, são um dos problemas cruciais do Distrito Federal, cidade planejada que enfrentou muito mal a passagem do tempo, possui aluguéis que estão entre os mais caros do país e expulsou a população mais pobre para uma periferia que, muitas vezes, está além de suas próprias fronteiras (o "entorno", cinturão de municípios goianos e mineiros que se tornaram cidades-dormitório de Brasília). A categoria "outros", muito heterogênea, abriga temas como direitos do consumidor, direitos dos homossexuais, direitos dos trabalhadores e saneamento.

Tabela 4: Inserções com apelo temático de candidatos à Câmara Legislativa do HGPE noturno de 2006

\begin{tabular}{l|l|l}
\hline educação & 214 & $25,4 \%$ \\
\hline trabalho/emprego/renda/salário & 166 & $19,7 \%$ \\
\hline saúde & 153 & $18,2 \%$ \\
\hline segurança & 107 & $12,7 \%$ \\
\hline ética & 80 & $9,5 \%$ \\
\hline moradia/ocupação do solo & 74 & $8,8 \%$ \\
\hline
\end{tabular}




\begin{tabular}{l|l|l}
\hline justiça social/pobreza/inclusão social & 69 & $8,2 \%$ \\
\hline esporte/lazer & 52 & $6,2 \%$ \\
\hline meio ambiente/qualidade de vida/desenvolvimento sustentável & 43 & $5,1 \%$ \\
\hline juventude & 44 & $5,2 \%$ \\
\hline cultura & 38 & $4,5 \%$ \\
\hline direitos da mulher & 30 & $3,6 \%$ \\
\hline transporte & 26 & $3,1 \%$ \\
\hline idosos/aposentados & 23 & $2,7 \%$ \\
\hline criança e adolescente & 16 & $1,9 \%$ \\
\hline direitos dos deficientes & 14 & $1,7 \%$ \\
\hline cidadania & 13 & $1,5 \%$ \\
\hline impostos & 10 & $1,2 \%$ \\
\hline discriminação/preconceito (sobretudo racial) & 10 & $1,2 \%$ \\
\hline família & 10 & $1,2 \%$ \\
\hline fiscalização do governo & 10 & $1,2 \%$ \\
\hline pequenas empresas & 9 & $1,1 \%$ \\
\hline turismo & 9 & $1,1 \%$ \\
\hline cidades satélites & 7 & $0,8 \%$ \\
\hline direitos dos presidiários & 7 & $0,8 \%$ \\
\hline outros & 113 & $13,4 \%$ \\
\hline
\end{tabular}

Fonte: pesquisa "Determinantes de gênero, visibilidade midiática e carreira política no Brasil"

Quando é introduzida a variável sexo, algumas diferenças notáveis são percebidas. Em temas como educação, saúde ou ética, carros-chefe da campanha na televisão, a proporção de inserções de homens e mulheres acompanha a média geral (elas respondem por $22 \%$ do total das inserções com apelo temático, ligeiramente acima de sua participação no total de candidatos). Mas as mulheres estão bastante sobre-representadas quando os temas são seus próprios direitos (66,7\% das inserções são de candidatas do sexo feminino) ou crianças e adolescentes (56,3\%). E sub-representadas em temáticas como meio-ambiente $(9,3 \%)$, segurança $(15 \%)$ e trabalho, emprego, renda e salário $(15,1 \%)$.

Como os números absolutos são pequenos, é possível que a presença de um ou dois candidatos vinculados a uma temática 
desequilibre as porcentagens. De maneira geral, porém, o quadro corresponde à noção de que as mulheres se vêem constrangidas a se associar às questões "femininas", de menor prestígio no campo político. A percepção convencional da mulher como cuidadora, preocupada com o bem-estar dos mais frágeis, condiciona sua inserção na disputa política e o progresso posterior da carreira. Ainda que as questões identificadas como "femininas" possam ser (e de fato sejam) de grande importância, elas são desvalorizadas simbolicamente dentro do campo ${ }^{12}$.

Há uma ampla literatura, sobretudo nos Estados Unidos, que vincula escolhas temáticas em campanhas eleitorais a estereótipos de gênero. As mulheres apelariam com mais frequiência para temáticas tradicionalmente vinculadas a elas, como família, assistência social, emprego, educação e seus próprios direitos, sabendo que são de antemão vistas como menos competentes para tratar de economia ou segurança (temática que, nos EUA, inclui a defesa externa). A estratégia de lutar contra os estereótipos geraria, em média, resultados eleitorais inferiores (ver DARCY, WELCH \& CLARK, 1994; KAHN, 1996; IYENGAR et. al., 1997; SELTZER, NEWMAN \& LEIGHTON, 1997; FOX \& OXLEY, 2003; HERRNSON, LAY \& STOKES, 2003; DOLAN, 2004; SANBONMATSU, 2006). A pesquisa no Distrito Federal confirma, em linhas gerais, a associação entre opções por temáticas de campanha e estereótipos de gênero. Mas confirma também que as conclusões estadunidense não podem simplesmente ser transferidas para as condições, bem distintas, da competição eleitoral no Brasil. Não apenas as temáticas relevantes são diferentes (bem como sua distribuição estereotipada entre os sexos), mas também a dinâmica eleitoral, sob regime de representação proporcional e no quadro do HGPE, é diversa.

Passando para a clivagem por posição partidária, verifica-se que a esquerda concentra temas como cidadania, empresas públicas (100\% dos casos em ambos), discriminação/preconceito (90\%), fiscalização do governo $(80 \%)$, cultura $(63,2 \%)$, direitos da mulher $(56,7 \%)$ e meio-ambiente $(55,8 \%)$, todos bem acima da proporção

12 Ver, por exemplo, Miguel, 2001; para abordagens empíricas na política brasileira, Barreira, 2006, e Miguel e Feitosa, 2009. 
geral de 35,2\% de inserções com apelos temáticos por candidatos de partidos de esquerda. Mas aparece menos quando o tema é idosos/aposentados (13\%), impostos, família ( $20 \%$ em cada), moradia/ ocupação do solo $(20,3 \%)$, trabalho/emprego $(22,9 \%)$ e segurança $(24,3 \%)$. Os candidatos dos partidos de centro aparecem abaixo da proporção geral em temas como cultura $(5,3 \%)$, esporte/lazer $(5,8 \%)$ e juventude $(6,8 \%)$, o que talvez se explique pelo fato de que esse agrupamento não inclui pequenos partidos, só PMDB e PSDB. Como nas grandes legendas a disputa por candidatos é mais acirrada, não há espaço para postulantes vinculados a temáticas marginais e de pouco potencial eleitoral.

Entre os temas mais presentes no HGPE, "impostos" se associa à maior votação média - os candidatos que dele trataram obtiveram, em média, 10529 votos, contra, na outra ponta, apenas 218 daqueles que enfocaram as cidades satélites.

\section{Conclusões}

Não há a pretensão de generalizar conclusões extraídas de uma única campanha eleitoral. A pesquisa indica com clareza, porém, que diferentes candidatos têm usos diferentes para o HGPE proporcional. Alguns poucos, privilegiados pelos partidos, escolhidos como "puxadores de voto", dispõem de tempo suficiente para apresentar diversos aspectos de uma plataforma de campanha. Outros, mais numerosos, buscam reforçar um componente de seu discurso que os vincularia a uma base eleitoral. Muitos se limitam a esperar que seu nome e número de urna se façam lembrados por meio da aparição na TV. E há aqueles, também, que recorrem a tentativas desesperadas de sobressair no meio do desfile de rostos que é a propaganda televisiva para as eleições proporcionais, ainda que o único recurso de que disponham seja a bizarria.

As duas vantagens, correntemente apontadas, do modelo brasileiro de propaganda eleitoral no rádio e na TV - redução do poder do dinheiro e do monopólio da produção da agenda pública pela mídia convencional - pouco se manifestam nas disputas aos cargos proporcionais. O HGPE reduz, sim, a influência do poder econômico, mas sobretudo por impedir que os candidatos mais abastados 
comprem espaço comercial da mídia. De resto, a campanha para estes cargos continua se apoiando fundamentalmente em recursos dispendiosos, como cabos eleitorais, comitês locais, "santinhos", outdoors, carros de som e concessão de favores, necessários para chegar ao eleitorado, uma vez que a presença na mídia eletrônica se mostra inefetiva. E os poucos segundos de que cada candidato tipicamente dispõe são insuficientes para sequer se esboçar um agendamento alternativo das questões públicas.

O aproveitamento do horário eleitoral reproduz, assim, problemas próprios do sistema eleitoral brasileiro. A representação proporcional favorece o multipartidarismo e o sistema de listas abertas coloca o eleitorado diante de uma miríade de opções: são muitos partidos, com muitos candidatos em cada lista. A legislação brasileira agrava o problema, permitindo que os partidos lancem candidatos em número superior ao das cadeiras em disputa. Assim, o sistema exige muito do eleitor, que idealmente seria capaz de avaliar todas as alternativas a seu dispor, mas também do candidato, que deveria fixar uma identidade distintiva em meio a seus muitos concorrentes ${ }^{13}$.

Eventuais mudanças no sistema eleitoral alterariam a utilização do tempo de TV e rádio para a eleição de deputados e vereadores, certamente aproximando-a da campanha para os cargos majoritários. A adoção do chamado "voto distrital", isto é, a votação majoritária em circunscrições uninominais em turno único, eliminaria a própria idéia de "eleição proporcional". A ausência de homologia entre a área de alcance das emissoras e os distritos eleitorais colocaria problemas. Já o fechamento das listas induziria à concentração da campanha, incluída a eletrônica, nos nomes mais bem colocados, com o virtual desaparecimento dos restantes. Num caso como no outro, porém, a ampliação da efetividade da propaganda eletrônica passa pela redução do elenco de opções à disposição do eleitorado, com consequiências significativas para o funcionamento da democracia e o exercício da accountability. 


\section{Referências}

ALBUQUERQUE, A.; STEIBEL, F. \& CARNEIRO, C.M. A outra face do horário gratuito: políticos e eleições proporcionais na televisão. Dados, vol. 51, no 2. Rio de Janeiro, 2008.

BARREIRA, I. Lideranças femininas no Congresso Nacional: performances, valores e habitus. Paper apresentado no XXX Encontro Anual da ANPOCS. Caxambu (MG), 24 a 28 de outubro de 2006.

DARCY, R., WELCH, S. \& CLARK, J.. Women, elections \& representation. Second edition, revised. Lincoln: University of Nebraska Press, 1994.

DOLAN, K. The impact of candidate sex on evaluations of candidates for the U. S. House of Representatives. Social Science Quarterly, vol. 85, no 1 . Hoboken, 2004.

FERNANDES, L. Muito barulho por nada: o realinhamento políticoideológico nas eleições de 1994. Dados, vol. 38, nํㅜ 1. Rio de Janeiro, 1995.

FOX, R. \& OXLEY, Z. Gender stereotyping in state executive elections: candidate selection and success. The Journal of Politics, vol. 65, no 3 . Tucson, 2003.

HERRNSON, P.; LAY, C. \& STOKES, A. Women running 'as women': candidate gender, campaign issues, and voter targeting strategies. The Journal of Politics, vol. 65, no 1 . Tucson, 2003, pp. 244-55.

IYENGAR, S. et al. Running as a woman: gender stereotyping in women's campaigns, In: NORRIS, P. (Ed.). Women, media, and politics. Oxford: Oxford University, 1994.

KAHN, K. The political consequences of being a woman. New York: Columbia University Press, 1996.

MIGUEL, L. Política de interesses, política do desvelo: representação e 'singularidade feminina. Estudos Feministas, vol. 9, no 1 . Florianópolis, 2001, pp. 253-67.

- Discursos cruzados: telenoticiários, HPEG e a construção da agenda eleitoral. Sociologias, no 11 . Porto Alegre, 2004.

- Accountability em listas abertas. Revista de Sociologia e Política, vol. 17. Curitiba, 2009, em fase de publicação. 
MIGUEL, L. \& FEITOSA, F. O gênero do discurso parlamentar: mulheres e homens na tribuna Câmara dos Deputados. Dados, vol. 52, no 1 . Rio de Janeiro, 2009, pp. 201-21.

MIGUEL, L. \& MACHADO, C. Um equilíbrio delicado: a dinâmica das coligações do PT em eleições municipais (2000 e 2004). Dados, vol. 50, no 4. Rio de Janeiro, 2007.

PANEBIANCO, A. Modelos de partido: organização e poder nos partidos políticos. São Paulo: Martins Fontes, 2005.

RODRIGUES, L. Partidos, ideologia e composição social. São Paulo: Edusp, 2002.

RUBIM, A. \& AZEVEDO, F. Mídia e política no Brasil: textos e agenda de pesquisa. Lua Nova, no 43. São Paulo, 1998, pp. 189-216.

SANBONMATSU, K. Where women run: gender \& party in the American states. Ann Arbor: The University of Michigan Press, 2006.

SCHMITT R.; CARNEIRO, L.P. \& KUSHNIR, K. Estratégias de campanha no Horário Gratuito de Propaganda Eleitoral em eleições proporcionais. Dados, vol. 42, no 2. Rio de Janeiro, 1999.

SELTZER, R.; NEWMAN, J. \& LEIGHTON, M. Sex as a political variable: women as candidates \& voters in U.S. elections. Boulder: Lynne Riener, 1997.

\section{Lista de siglas}

DF - Distrito Federal

HGPE - Horário Gratuito de Propaganda Eleitoral

PAN - Partido dos Aposentados da Nação

PCB - Partido Comunista Brasileiro

PCdoB - Partido Comunista do Brasil

PCO - Partido da Causa Operária

PDT - Partido Democrático Trabalhista

PFL - Partido da Frente Liberal

PHS - Partido Humanista da Solidariedade

PL - Partido Liberal 
PMDB - Partido do Movimento Democrático Brasileiro

PMN - Partido da Mobilização Nacional

PP - Partido Progressista

PPS - Partido Popular Socialista

PRB - Partido Republicano Brasileiro

PRONA - Partido de Reedificação da Ordem Nacional

PRP - Partido Republicano Progressista

PRTB - Partido Renovador Trabalhista Brasileiro

PSB - Partido Socialista Brasileiro

PSDB - Partido da Social-Democracia Brasileira

PSL - Partido Social Liberal

PSOL - Partido Socialismo e Liberdade

PSTU - Partido Socialista dos Trabalhadores Unificado

PT - Partido dos Trabalhadores

PTB - Partido Trabalhista Brasileiro

PTC - Partido Trabalhista Cristão

PTdoB - Partido Trabalhista do Brasil

PTN - Partido Trabalhista Nacional

PV - Partido Verde

\begin{abstract}
Discursive appeals in televised electoral campaigning

In proportional elections, usage of the "Public Time for Electoral Campaigning” (Horário Gratuito de Propaganda Eleitoral, or HGPE), shared by dozens or hundreds of candidates, loses its effectiveness. It does however have an important role to play, insofar as it informs the public that particular persons are candidates and reminds those who are already familiarized with the campaigns that candidacies have been established. This in turn serves to reinforce the voting intentions of voters who otherwise might neglect them. Moreover, we can suppose that, within the brief amount of time the HGPE awards to each candidate, the latter will try to reinforce the main elements of his/her discourse. This research, which analyzes the "Public Time for Electoral Campaigning" in the proportional elections in the Brazilian capital (Brasilia, the Federal District) attempts to provide an understanding of the strategies employed by political parties and candidates in their usage of the HGPE.
\end{abstract}

Keywords: political propaganda, media and politics, political discourse. 
